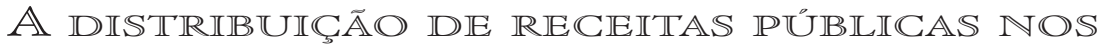 $\mathbb{M} U \mathbb{N I C I I P I O S ~ D O ~ E S T A D O ~ D A ~ B A I I A : ~ U M I A ~ A N A ́ L I S E ~}$ $C R I I T I C A \mathbb{D E}$ SUA $\mathbb{E} Q U I D A D E$
}

\author{
Neila Karolina Mendes Lira* \\ Augusto de Oliveira Monteiro** \\ Élvia Mirian Cavalcanti Fadul***
}

Restrino

presente artigo procurou avaliar o grau de equidade na distribuição de receitas entre os municípios do Estado da Bahia e a efetividade de sua utilização no período de 1998 a 2006. Para tal, foi analisada a distribuição e composição das receitas municipais e identificada a sua evolução. A demanda de serviços foi estimada de forma indireta com base na população de cada município. Em seguida, o grau de equidade foi analisado com base no cálculo da receita per capita de cada município. Por último, estimou-se o nível de efetividade dos serviços públicos ofertados mediante análise do Índice de Desenvolvimento Social (IDS) sendo efetuada uma análise de correlação entre a receita per capita e o IDS. Os resultados obtidos indicaram uma elevada disparidade de receitas entre os municípios, ancorada pela assimetria das transferências intergovernamentais, implicando em um nível muito baixo de equilíbrio na distribuição dos recursos públicos.

Palavras-Chave: Municípios. Finanças públicas. Receita pública. Equidade. Desenvolvimento social.

his paper aims to assess the degree of equilibrium in the distribution of revenues among municipalities of the State of Bahia and the effectiveness of its use in the period of 1998 the 2006. In order to do so, it analyzed the distribution and composition of municipal revenues and identified its evolution. The demand of services was evaluated on the basis of the population. Then, the degree of equilibrium was analyzed through the calculation of revenues per-capita of each municipality. Finally, effectiveness of public services was assessed by means of the Social Development Index (SDI) and an analysis of correlation between the revenues per-capita and SDI. Results showed high disparity among municipal revenues, deriving from huge intergovernmental transferences asymmetry, implying in a very low level of balance in the distribution of the public resources.

Key-Words: Municipalities. Public finance. Public revenue. Equity. Social development.

\footnotetext{
* Mestre em Administração, Universidade Salvador (UNIFACS)

Pesquisadora do Programa de Pós-Graduação em Administração, Universidade Salvador- LaureateInternationalUniversities.

E-mail: neilakarol@yahoo.com.br

**Doutor em Administração, Universidade Federal da Bahia (UFBA)/Boston University

Professor Titular do Mestrado em Administração, Universidade Salvador-LaureateInternationalUniversities.

E-mail: augusto.monteiro@unifacs.br

***Doutora em Urbanismo, Université Paris-Est Créteil-França eCoordenadora do Programa de Pós- Graduação em Administração, Universidade Salvador- LaureateInternationalUniversities.

E-mail:elvia@unifacs.br
} 
o regime federativo, a distribuição de receitas entre as esferas de governo deveria ocorrer com o propósito de evitar a existência de desigualdades inter e intra-regionais, através da definição adequada das competências fiscais, das compensações tributárias e das formas de cooperação entre os entes federados. Para tanto, a formalização e a especificação das relações entre esses governos podem acontecer através da utilização de constituições e/ou convenções, acordos e outros instrumentos de coordenação que demarquem o formato dessas interações.

No caso brasileiro, o modelo de financiamento da ação estatal e a organização das relações fiscais intergovernamentais seguem o disposto na Constituição Federal de 1988, a qual define as competências e limitações para a instituição de tributos, assim como a composição (arrecadação própria, devolução tributária, transferências, empréstimos e compartilhamento de receitas) e os percentuais das receitas públicas disponíveis para os diferentes governos que necessitam cumprir as suas funções básicas (alocativa, distributiva e estabilizadora). Cabe à Lei Complementar dirimir eventuais conflitos em matéria de legislação tributária, sem, contudo, afetar a soberania federal.

A literatura econômica examina o federalismo a partir dos supostos benefícios provenientes da descentralização fiscal, que compreende a provisão de bens públicos em consonância com as preferências dos cidadãos e, dessa forma, considera que a centralização deveria ocorrer apenas para oferecer benefícios coletivos. Com base nessa concepção, a investigação proposta utiliza os preceitos teóricos de Oates (1977), que considera fundamental a descentralização de poderes e encargos aos governos subnacionais para o alcance da eficiência alocativa, podendo obter vantagens por estarem próximos às demandas e fiscalização dos contribuintes locais. Não obstante, os governos locais possuem diferentes capacidades econômicas e, consequentemente, fiscais, e, ao mesmo tempo, demandam níveis mínimos de bens e serviços públicos, que em muitas vezes não conseguem prover sem a contribuição dos demais níveis de governo. Sendo assim, o Brasil, que apresenta variados níveis de renda per capita entre municípios, estados e regiões, necessita adotar sistemas de equalização que distribuam receitas e encargos de forma a reduzir as disparidades entre os governos subnacionais e fornecer condições favoráveis à prestação de serviços com um padrão ínfimo nacional.

Dessa forma, o objetivo geral deste trabalho consiste na análise da equidade na distribuição de receitas entre os municípios baianos, de modo a trazer evidências que ajudem a avaliar se a formatação atual do federalismo fiscal brasileiro possibilita a existência de uma repartição de recursos compatível com as necessidades das populações locais.

\section{Fedlerantismo Fiscall}

A adoção de um sistema político e jurídico-administrativo unitário ou federado pode ser influenciada por fatores históricos, políticos, geográficos, econômicos e culturais de determinado estado nacional. Não obstante a predominância de sistemas unitários como forma de organização estatal, o federalismo, como configuração de Estado, ganhou relevância e adeptos em países como, Estados Unidos da América (EUA), Austrália, Alemanha, Canadá, Brasil, Índia, China e Suíça.

A organização estatal através de uma federação, objetiva preservar as diversidades e garantir a unidade, visando evitar conflitos e permitir a cooperação entre os estados membros, principalmente em países com grandes extensões territoriais. A aceitação do arranjo federativo não significa que os resultados obtidos sejam idênticos em todas as nações, uma vez que, se por um lado permanece como traço semelhante à descentralização política, com intensidade diferente entre os países, por outro lado, cada nação possui características peculiares desde a sua formação.

As estruturas fiscais das federações são complexas variando entre os Estados federais, diferentemente do sistema unitário de governo que centraliza o processo 
orçamentário, a arrecadação e a execução do gasto - conservando a eficiência, na maioria dos casos. Segundo Prado (2006), as federações precisam de coordenação para garantir a autonomia dos entes federativos e um padrão uniforme de acesso aos serviços públicos, além de evitar os conflitos entre os níveis de governo.

O federalismo fiscal compreende a forma de repartição das competências (poderes para tributar), encargos (atribuição de gastos), repartição de receitas e mecanismos de ajustes do desequilíbrio gerado pela dissociação entre necessidades de gastos e receitas dos entes federados. Através da ilustração abaixo são apontadas algumas vantagens e desvantagens das possíveis opções de organização fiscal adotadas pelo Estado federal:

a) Centralização do sistema tributário (poder para arrecadar) no governo federal, que transfere parte da receita, de forma incondicional, para a execução de gastos efetuados pelos governos subnacionais. Apresenta vantagens ligadas à harmonização tributária, ou seja, uniformidade na aplicação de tributos em todo o território nacional e desvantagens relacionadas à perda de autonomia, eficiência e transparência;

b) A tributação é descentralizada, com a repartição de competências entre 0 governo central e os governos subnacionais, e os orçamentos dos estados membros possuem poder de escolha de gastos. Oferece a desvantagem de promover disparidades regionais devido à variação na capacidade econômica e de gastos dos governos locais, ao mesmo tempo em que permite a existência de autonomia, eficiência e controle pelos entes subnacionais.

Certamente, existem divergências de interesse entre os governos subnacionais, cada qual com diferente possibilidade econômica, uns desejando ampliar a devolução tributária, de acordo com a sua contribuição na parte arrecadada, e outros almejando a elevação das transferências efetuadas pelo governo central. Dessa forma, os sistemas federados necessitam buscar formas de equalização fiscal com o objetivo de reduzir as disparidades entre governos subnacionais, de forma a propiciar a prestação de serviços públicos conforme um padrão mínimo nacional, considerando para tanto, a totalidade das receitas, o custo médio nacional desses serviços, e as condições econômicas e tributárias de todas as regiões do país.

Existe a possibilidade de o equilíbrio fiscal ocorrer mais facilmente através da centralização da arrecadação (legislação) nos níveis superiores de governo, com vistas à promoção da harmonização tributária e da descentralização de gastos nos níveis inferiores de governo, devido à proximidade das preferências dos cidadãos. Destarte, o ajustamento fiscal entre as jurisdições aconteceria através das transferências governamentais.

Quando o assunto é determinar o responsável pela execução das atribuições de encargos e tributação, existem duas formas básicas de atribuição de poderes em um sistema federal, citadas por Prado (2006), as quais podem ser resumidas da seguinte forma:

- Poderes ligados à distribuição de encargos, isso é, determina quem executará o serviço público: é o chamado poder concorrente, devido à multiplicidade de responsáveis (vários níveis de governo) para o suprimento de um mesmo pleito; apresenta dificuldade para fiscalizar o oferecimento do serviço e para realizar a coordenação entre os vários níveis de governo. Exemplos de países que adotam poderes concorrentes: EUA, Alemanha, Austrália e Índia;

- Poderes que garantem a exclusividade na prestação do serviço e na sua tributação: denomina-se poder exclusivo, com a proibição de participação dos demais níveis. Esse poder permite controlar mais facilmente o provimento dos serviços. Exemplos de países que adotam o poder exclusivo: Canadá, Suíça e Bélgica. 
Vale observar que o sistema federativo-fiscal brasileiro ostenta poderes tributários exclusivos e encargos concorrentes. O Estado federal apresenta mais de um orçamento sobre o mesmo território, com a existência de diferentes preferências e desenvolvimentos econômicos locais. Logo, a distribuição dos recursos em uma federação geralmente é feita através da atribuição de poderes para tributar e das transferências intergovernamentais, sendo que essas últimas ganharam destaque com a centralização de recursos nos governos centrais, bem como pela recente descentralização dos encargos para os governos subnacionais (geralmente não tinham a correspondente competência para tributar).

Lima (2003, p. 128) resume as razões usualmente utilizadas na literatura econômica para explicar a existência das referidas transferências intergovernamentais: internalização de externalidades a outras jurisdições; melhoria do sistema tributário como um todo; correção de ineficiências na oferta de equilíbrio de bens públicos locais; e equalização fiscal entre jurisdições. As três primeiras relacionam-se com a eficiência econômica, uma vez que o governo central pode incentivar o fornecimento de bens e serviços que atendam as necessidades de várias localidades; aperfeiçoar a administração dos tributos, através, por exemplo, de uniformidade de alíquotas e pela fiscalização; e para alcançar um padrão nacional de oferta de bens públicos. A última delas tem forte relevância em federações com consideráveis desigualdades sociais entre as suas localidades.

As transferências podem ser realizadas através da brecha vertical (de cima para baixo), que consiste na transferência de recursos por governos localizados em níveis superiores com a finalidade de complementar o financiamento dos gastos dos governos subnacionais, ou através do compartilhamento horizontal, que significa o ajuste das capacidades entre unidades que pertencem ao mesmo nível de interesse. A brecha vertical existente nas federações não representa necessariamente um desequilíbrio, visto que centralizar poder de arrecadação nos governos superiores e responsabilidade de gastos nos governos inferiores pode representar uma alternativa mais viável. Sendo assim, as transferências verticais podem ser mais eficientes na redução das desigualdades horizontais, na execução de programas nacionais de benefícios coletivos e no atingimento de maior eficiência com a concentração tributária.

Sérgio Prado (2006) relaciona quatro causas básicas da brecha vertical, sintetizadas a seguir:

- Atuação dos governos centrais no pós-guerra: com a criação do Estado do Bem-Estar Social, os estados nacionais ficaram fortalecidos, principalmente nos países desenvolvidos, permanecendo potentes, mesmo com a descentralização;

- Eficiência na atribuição de encargos e tributos: do lado dos encargos, fatores como a globalização e as privatizações fragilizaram o poder dos governos nacionais, com o incentivo à descentralização de encargos, a partir das últimas duas décadas. Com a execução de gastos na área social, induziu-se a descentralização de responsabilidades nos governos subnacionais devido à proximidade das demandas. Do lado dos tributos, a eficiência alocativa, a "guerra fiscal" e o custo para o contribuinte incentivaram a centralização da arrecadação no governo central;

- Demandas por equidade horizontal: o efeito reprodutivo da capacidade econômica na capacidade fiscal provoca disparidades regionais, na medida em que varia a arrecadação. Assim sendo, os governos que fazem parte de uma federação deveriam oferecer serviços públicos com um mínimo de equidade em termos de quantidade e qualidade, sem elevar a carga tributária das localidades mais pobres. Por conseguinte, uma das alternativas seria a delegação de poderes, para o governo central arrecadar mais do que necessita com a finalidade de executar a função equalizadora entre as jurisdições (equidade horizontal), através das transferências; 
- Função do governo central como gestor do gasto: na maioria das federações, o governo central faz uso das transferências condicionadas para financiar gastos dos governos subnacionais com finalidade de angariar benefícios de interesse nacional, como os programas de saúde, educação e infraestrutura.

Para a análise do grau de equidade na distribuição de receitas entre os municípios baianos, faz-se imprescindível a descrição das modalidades de transferências intergovernamentais existentes na federação brasileira. Essa exposição permite compreender o grau de autonomia dos governos subnacionais diante da capacidade para tributar, ao tempo em que traduz o funcionamento das relações intergovernamentais numa federação. A depender da finalidade para a sua existência, as transferências podem ser classificadas como: livres ou condicionadas (ligadas à autonomia orçamentária), devolutivas ou redistributivas (referentes à apropriação econômica) e legais ou voluntárias (de acordo com o abono de recursos), diferenciando uma das outras, de acordo com o resumo feito a partir dos escritos de Prado (2006):

- a) Livres: não requerem o controle do governo central, passando a fazer parte do orçamento do governo favorecido, que define sua aplicação;

- b) Condicionadas: com finalidade pré-estabelecida, geralmente de padronização da oferta de serviços público na federação, com menor autonomia dos governos subnacionais e maior controle do governo central, possuindo a vantagem de cobrar a realização de determinado serviço.

- c) Devolutivas: o governo central arrecada e devolve para a jurisdição, de acordo com a origem da arrecadação. Não ameniza as disparidades regionais, tendo em vista que o repasse ocorre em consonância com a atividade econômica de cada localidade;

- d) Redistributivas: têm a intenção de repassar para os entes subnacionais, receitas sem vinculação com suas capacidades econômicas (devolução ou compensação tributária). E para que também assumam o papel de equalizadoras, promovendo a redução das disparidades entre as unidades da federação, pode-se inserir a participação do governo central no repasse de recursos para as localidades que não possuem a capacidade fiscal, buscando aproximar os recursos à disposição das unidades federadas;

- e) Legais: as transferências feitas pelo governo central estão de acordo com o determinado na Constituição ou legislação, com penalidade prevista em caso de descumprimento; de um lado, esse tipo de cessão tem a vantagem de evitar a dependência política, e do outro lado, apresenta a desvantagem de perder a flexibilidade;

- f) Voluntárias: são os chamados convênios firmados entre o governo central e os demais níveis de governo. Financiam serviços específicos, sem a exigência legal.

No molde do Brasil, os fundos de participação são redistributivos; a Cota-Parte do Imposto sobre Circulação de Mercadorias e Serviços (ICMS) é, em sua maior parte, devolutiva; convênios e emendas de deputados são voluntárias; e o Fundo de Manutenção e Desenvolvimento da Educação Básica e de Valorização dos Profissionais da Educação (FUNDEB) e o Sistema Único de Saúde (SUS) são transferências condicionadas.

Portanto, as federações enfrentam questões cruciais que precisam ser avaliadas com o propósito de escolher a alternativa que favoreça a equidade fiscal, ao tempo em que a legalidade das transferências de recursos, que permite a estabilidade no fluxo de entrada de recursos públicos, também reduz a tempestividade na adaptação das circunstâncias e possibilita diferentes ofertas de serviços. Ainda assim, se a devolução 
de tributo ocorrer intensivamente, menor será a probabilidade de redistribuição pelos governos centrais.

Em um contexto de globalização, a inovação e a oportunidade de se oferecer produtos e serviços de acordo com as especialidades e preferências dos cidadãos de determinada localidade, defende a competição como ferramenta de eficiência do gasto público. A Teoria Econômica exposta por Tiebout (1956 apud OATES, 1977, p. 29) apresenta essa concepção, ao conceber que os governos locais podem propiciar os serviços adequados à permanência de indivíduos naquela jurisdição.

Tanzi (1988 apud SILVA 2005, p. 132) ressalta o imperativo da existência da harmonização e coordenação fiscal entre as jurisdições, diante da plena mobilidade de fatores e transmissões de externalidades entre os espaços econômicos subnacionais. Por conseguinte, o governo central pode exercer um importante papel na coordenação entre os níveis de governo, com a finalidade de incentivar a articulação conjunta para a realização de políticas públicas. Abrucio $(2005$, p. 9$)$ também ressalta que a atuação do governo central ou de outras instâncias federativas não precisa ferir os princípios básicos do federalismo, como a autonomia e os direitos originários dos governos subnacionais, a barganha e o pluralismo associados ao relacionamento intergovernamental e os controles mútuos.

O federalismo, sob a ótica econômica, representa as decisões referentes aos níveis de provisão de determinados serviços públicos para uma jurisdição específi$\mathrm{ca}$, que refletem o grau de interesse dos seus habitantes. Por conseguinte, Oates (1977, p. 36) destaca que o que importa é o grau em que as decisões próprias são refletidas e que as estruturas constitucionais têm importância, na medida em que afetam a adequação da provisão dos serviços públicos às preferências locais. Portanto, Oates (1977, p. 38) pondera que o problema teórico central do federalismo é a escolha da estrutura ótima do setor público referente às atribuições das responsabilidades na tomada de decisões sobre funções específicas, entre os diferentes níveis de governo.

Oates (1977, p. 31-33) considera que a organização federal apresenta benefícios, pelo menos, econômicos, através da associação do governo unitário e da descentralização extrema. Cada nível de governo pode escolher a função pública mais apropriada às preferências dos cidadãos locais e as suas competências. No entanto, os governos locais devem se basear, exclusivamente, nos programas de ingressos e gastos públicos, enquanto que as medidas de estabilização cabem ao governo central. Sendo assim, o modelo federalista fiscal de Oates (1977, p. 56-60), considerado ideal, prevê uma correspondência perfeita entre a provisão de bens pelo setor público e as preferências dos agentes econômicos de uma determinada localidade. E aqui reside o Teorema da Descentralização de Oates, definindo que se existir uma maior diversidade nas demandas dos consumidores, os ganhos de bem-estar serão maiores com o fornecimento descentralizado de um determinado bem público, devendo ser atribuição do governo federal, o aprovisionamento de bens que são uniformes nas escolhas das localidades.

\section{Fedleranlisino Fiscall Brasileiro}

O modelo federativo fiscal brasileiro, adotado com a promulgação da nova carta constitucional, concedeu novamente espaço para a descentralização, objetivando a eficiência da provisão de serviços públicos e relegando a tendência de centralização defendida pelo Regime Militar. A partir de então, o regime fiscal necessitaria harmonizar a disponibilidade de recursos e os encargos repassados aos entes federados.

A transição para o regime democrático elevou a pressão dos governos subnacionais por uma maior participação nas receitas tributárias, incrementando, dessa forma, o percentual de transferências para os estados e especialmente para os municípios. Ainda assim, em referência à caracterização do federalismo brasileiro atual, Souza (1999) pondera o seguinte: 
O federalismo brasileiro incorpora hoje múltiplos centros de poder e pode ser caracterizado como um sistema complexo de dependência política e financeira entre esferas de governo, por caminhos e capacidades diferenciadas na provisão de serviços públicos e por grandes disparidades entre as regiões e no interior de uma mesma região.

Em alusão à coordenação federativa no período de 1995 a 2002, foram adotadas as seguintes estruturas pelo governo federal, visando coordenar as relações intergovernamentais e a descentralização, as quais podem ser sintetizadas, com base nos escritos de Abrucio (2005, p. 20-24):

- A atual situação de estabilização permitiu o ajuste da descentralização em várias políticas públicas, com a finalidade de ajustar a transferência de recursos aos governos subnacionais;

- A descentralização ocorreu ajustada à reformulação do Estado, que se iniciou com a redução da permissão para a criação de déficit pelos governos subnacionais, prosseguindo com a modernização da estrutura fazendária e com a aprovação da Lei de Responsabilidade Fiscal (LRF), e se estendeu até a implementação de medidas de subsídio na esfera previdenciária;

- O aspecto democrático da descentralização exigiu que a transmissão de recursos fosse condicionada à presença e fiscalização da comunidade local, especialmente através dos Conselhos de Políticas Públicas;

- A coordenação de políticas públicas realizadas de acordo com metas ou padrões nacionais, garantindo a autonomia dos governos subnacionais diante da gestão pública, além da utilização de instrumentos de redistribuição horizontal, como o Fundo de Desenvolvimento do Ensino Fundamental e de Valorização do Magistério (FUNDEF), atual FUNDEB;

- Adoção de políticas de distribuição direta de renda à comunidade, como o Programa de Erradicação do Trabalho Infantil (PETI), o Programa Renda Mínima e o Programa Bolsa Escola, visando resolver problemas redistributivos;

- Utilização frequente de novas leis ou modificações constitucionais referentes ao federalismo brasileiro;

- Desenvolvimento de sistemas avaliadores de políticas descentralizadas, principalmente na esfera educacional.

Com a análise do modelo federativo adotado nesse período, Abrucio (2005, p. 24) ressalta os seguintes problemas ocorridos na federação brasileira: repartição de uma determinada política pública em vários órgãos; trituração das políticas de renda; falta de ponderação dos espaços descentralizados; quase inexistência de fóruns intergovernamentais; despreocupação com a harmonização tributária; enfraquecimento das políticas regionais e urbanas; e efeitos negativos obtidos com a recentralização de receitas.

No tocante à repartição das receitas tributárias na federação brasileira, percebemos uma estreita vinculação política - centralização do poder político - com o montante repartido entre os níveis de governo. Ante ao exposto, Rezende e Afonso (2004, p. 313) realizam um cronograma de partilha das receitas tributárias, a partir da Constituição de 1967, conforme o resumo a seguir:

- 1964-1967: a reforma tributária foi feita pelo regime militar, destinando $20 \%$ dos impostos federais (IPI e IR) aos fundos estaduais e municipais, de acordo com uma fórmula própria;

- 1968: redução em 50\% dos impostos federais transferidos aos estados e municípios, ao tempo em que foi criado um Fundo Especial formado com 
$2 \%$ desses impostos visando reduzir a autonomia dos governos subnacionais;

- 1975-1983: progressiva elevação da transferência de recursos da União para os FPEs e FPMs através de Emendas Constitucionais promulgadas em 1975 e 1980;

- 1984-1988: com a democratização, ocorreu a mobilização dos estados e municípios para elevarem suas participações nas receitas federais, chegando a possuírem $14 \%$ e $16 \%$ dos impostos federais na composição do FPE e FPM, respectivamente;

- 1988: com a promulgação da Constituição de 1988, os impostos federais compunham 22,5\% dos FPE e FPM já no ano de 1993. Os estados foram compensados com a perda da arrecadação própria das exportações de bens manufaturados, com a existência de um fundo formado com $10 \%$ do IPI. Ademais, 3\% do IR e do IPI foram destinados ao fundo de desenvolvimento regional para financiar investimentos nas regiões Norte, Nordeste e Centro-Oeste.

Em referência à instituição da Carta Magna de 1988, Rezende e Oliveira (2003, p. 14-15) ressaltam que não houve acordo negociado para redefinir as atribuições dos entes federados no exercício de políticas públicas. Adversamente, descentralizaram recursos a favor dos estados e municípios e desconcentraram encargos, sem definir antecipadamente as normas precisas de cooperação financeira. A conseqüência dessas decisões foi o desequilíbrio do regime de partilhas e transferências de receitas na federação brasileira, com o reflexo negativo sobre as políticas de desenvolvimento, inclusive no tocante aos incentivos fiscais para o progresso regional, como pode ser exemplificado, através da modificação da legislação do Imposto de Renda (IR) e da redução de recursos para os fundos que promoviam o desenvolvimento regional.

Rezende e Oliveira (2003, p. 25) enfatiza que o recente federalismo fiscal ainda repousa no modelo firmado em 1967, com ressalvas relacionadas ao ambiente econômico. A desfiguração sofrida em 1988, não reformulou os fundamentos desse molde, sendo executados apenas alguns ajustes que não foram suficientes para redefinir a atuação dos entes federados frente à formulação de políticas públicas necessárias à evolução do país.

Por outro lado, é importantíssimo ressaltar que um sistema de partilhas em um modelo federativo não deveria afastar-se de um compromisso com o equilíbrio socioeconômico da federação e com a justiça social, ainda que não eliminadas em sua plenitude as disparidades regionais. Nesse sentido, Moraes (2001, p. 115) aponta que

\footnotetext{
[...] quando se pretende praticar uma política redistributiva [...], o que se busca, na verdade, não é eliminar inteiramente os hiatos entre necessidades e capacidades financeiras, mas sim fortalecer as instâncias mais fracas, a fim de que possa ser alcançado, em todo o território nacional, um padrão mínimo de cumprimento das funções públicas mais essenciais.
}

Em trabalho posterior, Rezende (2006, p. 97-98) volta a destacar a expressividade do chamado "desequilíbrio horizontal", conformado pelas disparidades entre a disponibilidade de recursos financeiros per capita entre os vários estados e municípios da federação brasileira, destacando que "as evidências desses desequilíbrios foram apresentadas em estudos (PRADO et al., 2003) e se manifestou por enormes e inexplicáveis assimetrias encontradas nos valores dos orçamentos estaduais e municipais em relação aos tamanhos das respectivas populações".

Em contraponto a essa constatação, há quem questione acerca de uma possível ineficiência fiscal dos entes federativos, considerando-a, ao mesmo tempo, uma causa dos desequilíbrios horizontais e um efeito da acomodação decorrente da uti- 
lização de instrumentos redistributivos e compensatórios, afetando as condições de competição inter-regional. Para Lucas (2010, p. 208), "[...] quando temos governos não benevolentes, transferências podem ser utilizadas para financiar, por exemplo, subsídios para grupos de interesses particulares [...]". No caso do Brasil, no entanto, a elevadíssima disparidade econômica entre os municípios impõe àqueles mais pobres uma quase impossibilidade de auferir uma receita tributária expressiva, haja vista a virtual inexistência de atividade econômica relevante a ser tributada em seu território.

E, finalmente, Rezende (2012, p. 19), ao reconhecer novamente a gravidade do problema em tela, ressalta a necessidade de uma ampla reforma fiscal, sem a qual "[...] não é possível corrigir uma enorme injustiça social que vem se acumulando ao longo do tempo. Uma injustiça que se manifesta sob a forma de desigualdades de acesso do cidadão brasileiro a padrões adequados de provisão de serviços públicos essenciais para nivelar as oportunidades de ascensão social". Em especial no Estado da Bahia, esta pesquisa procura descortinar a magnitude dessas desigualdades.

\section{MIetodologial}

Para fins de verificação da equidade na distribuição de receitas entre os municípios baianos, foram analisados os dados relativos às suas finanças públicas (receitas realizadas) e aos seus indicadores demográficos e de desenvolvimento social, uma vez que apenas a avaliação do montante real de recursos disponíveis não seria suficiente para se inferir sobre o atendimento das necessidades sociais desses municípios. Os bancos de dados utilizados foram obtidos através dos endereços eletrônicos da Secretaria do Tesouro Nacional (STN) e da Superintendência de Estudos Econômicos e Sociais da Bahia (SEI). Neles, consta a relação dos municípios do Estado da Bahia (aproximadamente 400 , dentre os quais, provalvemente foram excluídos aqueles que foram criados recentemente, após o período de avaliação, e os que não encaminharam as suas contas a esses órgãos), além da composição de suas receitas totais, do indicador populacional, do IDS calculado pela SEI nos anos de 1998, 2000, 2002 e 2004 (confeccionado a cada dois anos), do Produto Interno Bruto (PIB) do país e do Índice de Preço ao Consumidor Amplo (IPCA).

A avaliação fiscal dos municípios do Estado da Bahia ocorreu por meio da análise da evolução da receita total no período de 1998 a 2006, utilizando-se os bancos de dados fornecidos pela STN e SEI, relacionando-a ao PIB nacional e ao IPCA - índice de referência para a formação da taxa básica de juros da economia brasileira -, com o objetivo de se constatar qual o percentual da receita pública, em termos reais, sobre o PIB que está à disposição das cidades baianas. Por conseguinte, esse estudo também contribuiu para se avaliar o esforço fiscal dos governos municipais diante de diferentes critérios de repartição dos recursos públicos no país.

Com a finalidade de se analisar, detalhadamente, a relação existente entre a receita per capita disponível e os indicadores de desenvolvimento social desses municípios, e, dessa forma, a qualidade dos seus gastos, escolheu-se como referência o ano de 2004, por ser esse o último ano com o IDS calculado e divulgado pela SEI. Primeiro, buscou-se destacar o montante da receita total disponível naquele ano, com vistas a esclarecer como ocorre o financiamento dos gastos nos municípios baianos através da identificação da composição dos seus recursos públicos (receitas próprias, de transferência, financeiras, e de operações de crédito). Em seguida, analisou-se a demanda de recursos, com base no critério populacional, com vistas a avaliar a correlação entre a destinação de receitas públicas e as necessidades sociais dos municípios baianos. A avaliação da relação entre a dependência financeira e o indicador demográfico foi feita através da análise da distribuição da receita própria entre os municípios baianos que possuem os menores e maiores percentuais de demandas por bens e serviços públicos.

O estudo da correlação entre a distribuição da receita e as necessidades sociais dos municípios baianos foi realizado com o objetivo de se avaliar o grau de equidade nessa distribuição, através da identificação da evolução ocorrida de 1998 até 2006 
nas receitas per capita, a preços correntes, visando constatar se houve incremento na capacidade de financiamento dos gastos dos municípios baianos e identificar em que medida os recursos disponíveis foram suficientes para atender as demandas de suas populações. A análise da associação entre as variáveis Receita e População permitiu verificar se a distribuição da receita per capita ocorre dentro da normalidade proposta por Gauss, a qual considera os seus valores médios e a variância, propondo uma distribuição esperada. Em outras palavras, dada a variância resultante de uma análise estatística, estudou-se a probabilidade de se possuir determinadas receitas per capita de acordo com uma distribuição normal (em torno da média dos valores apreciados).

Já a análise da efetividade na prestação dos serviços públicos através da verificação do IDS dos municípios baianos, calculados pela SEI, permitiu avaliar os efeitos da distribuição da receita pública sobre a melhoria dos indicadores sociais frente à política federativa brasileira de beneficiar os municípios menores. Em seguida, buscou-se analisar a composição dos indicadores municipais de desenvolvimento social, com o objetivo de se identificar qual (is) a relação existente entre os índices que compõem o IDS e o atendimento das necessidades sociais das populações, através da identificação dos setores sociais atendidos.

E por fim, o estudo da qualidade do gasto público relacionou a receita per capita real disponível e o IDS dos municípios baianos com o propósito de avaliar a equidade na distribuição da receita pública, relacionando-se os municípios que detêm melhores IDS com diferentes receitas per capita. Dessa forma, foram realizadas análises de correlação e regressão com a finalidade de comprovar a relação porventura existente entre as variáveis dependente (IDS) e explicativa (receita per capita), através da identificação da relação numérica linear - coeficiente de Pearson $(r)$ e do coeficiente de determinação $\left(r^{2}\right)$.

\section{Amalise dlos Resrultados}

No período em estudo, a receita total média apresentou um acréscimo de aproximadamente $\mathrm{R} \$ 20$ milhões, o que representa uma elevação de $70 \%$ nos recursos disponíveis para os municípios do Estado da Bahia. Todavia, o efeito inflacionário reduziu a capacidade desses governos municipais de financiarem seus gastos, podendo, dessa forma, ser considerado um incremento modesto diante do número significativo de municípios baianos. Registra-se ainda que a inflação ocorrida nos anos 2001, 2002 e 2003 provocou a interrupção na elevação contínua da receita total real média dos municípios do Estado da Bahia, iniciada em 1998.

A análise sobre a participação da receita pública média, a preço corrente, no PIB brasileiro, evidencia a existência de uma forte concentração de recursos em estados que dispõem de uma maior capacidade econômica. Nos anos de 1998 e 2005, essa receita média equivaleu a $30,88 \%$ e $34,53 \%$ do PIB, respectivamente, sendo que a parcela pertencente ao conjunto de municípios baianos correspondeu a somente $0,87 \%$ e 1,17\% do PIB do país nos anos de 1998 e 2006 (a STN não informou ainda, em seu site, a receita total do Brasil no ano de 2006, e por essa razão não foram expostos os dados desse ano).

Em se tratando de repartição equânime da receita pública, de acordo com as necessidades sociais, apesar da evolução de quase $260 \%$ no total de recursos disponíveis para o conglomerado de municípios baianos, no período de 1998 até 2005, os valores identificados correspondem a somente $13,7 \%$ e $16 \%$ da receita per capita real disponível no Brasil.

A composição das receitas públicas municipais, nos anos de 1998 a 2006, permaneceu praticamente inalterada em relação à estrutura de financiamento do gasto público: $80 \%$ formada por receitas de transferências e aproximadamente $20 \%$ por receitas próprias. Em detalhes, a receita total possui no ano de 1998, por exemplo, em sua estrutura, $29 \%$ de recursos oriundos do FPM, $20 \%$ da cota do ICMS, $13 \%$ de outras receitas de transferências, $8 \%$ de Fundef, 5\% de outras transferências de 
capital; e outras receitas próprias, 7\% de ISS, 4\% de IPTU, 3\% do SUS, e $1 \%$ de cota do IPVA e Lei Complementar 87-96 ICMS.

Dessa forma, a partir de 2004, apesar do incremento considerável de aproximadamente $\mathrm{R} \$ 10$ milhões no total das receitas públicas médias disponíveis para os municípios baianos, descontado o efeito inflacionário, não se alterou a dependência em relação ao repasse de transferências intergovernamentais. Nesse ano, os municípios menores (em número de habitantes) receberam em média $8 \%$ dos recursos totais para atender a $4 \%$ da população do Estado da Bahia, enquanto Salvador dispunha dos mesmos $8 \%$ para cuidar de $19 \%$ da população. (SUPERINTENDÊNCIA..., 2008)

Outra parcela das receitas, as próprias, no período de 2001 a 2004, representou aproximadamente $20 \%$ dos recursos totais disponíveis para os municípios com mais de 100 mil habitantes, sendo que os municípios baianos mais populosos possuíam uma parcela proporcionalmente maior das receitas próprias, na composição de suas receitas totais. Portanto, contrariando a argumentação de alguns autores de que a competência tributária nas mãos desses governos contribuiria para financiar seus gastos, verifica-se que houve um fraco desempenho na arrecadação de suas receitas próprias entre os anos de 1998 e 2000, apresentando perdas de R\$176,2 milhões no conjunto do Estado da Bahia e de R\$ 61,9 milhões em Salvador (SUPERINTENDÊNCIA..., 2008), favorecido pela política federativa fiscal brasileira.

Existe a predominância de municípios que possuem populações com menores números em todo o Estado da Bahia, principalmente os que estão localizados entre 10 e 30 mil habitantes. De uma forma ampla, pode-se constatar que a demanda por recursos nesse estado acompanha a distribuição populacional quando se considera o conjunto de municípios que possuem acima 50 mil habitantes. Em outras palavras, metade da população baiana está concentrada em apenas 38 municípios, que centralizam $48 \%$ das receitas totais médias, visando o atendimento de suas demandas sociais. (SUPERINTENDÊNCIA..., 2008)

Entretanto, têm-se duas situações diferenciadas quando se considera a outra metade da população dos municípios baianos: de um lado, encontram-se aqueles municípios que possuem de 10 a 30 mil habitantes, que detêm um montante de recursos acima das suas necessidades sociais (considerando o fator populacional); do outro lado, estão os $17 \%$ da população do estado que possuem receitas totais médias inferiores às suas populações, incluída aqui a capital baiana. No caso específico de Salvador, a situação é mais grave em função da sua posição no estado, que favorece a elevação de seus problemas sociais à medida que precisa atender as demandas de outros habitantes do Estado da Bahia.

Verificou-se, ainda, que no ano de $2004,47 \%$ da população dos municípios baianos estava compreendida na faixa etária de até 19 anos, onde se localizam os habitantes que necessitam de uma aplicação de recursos públicos no ensino básico e fundamental, bem como na orientação e prevenção de doenças, ao tempo em que a população mais velha, com idade acima de 65 anos, abrange $0,6 \%$ do contingente populacional do Estado da Bahia, exigindo gastos maiores com serviços de saúde e com a previdência social, seja por meio de auxílios doença ou por aposentadoria. Destaca-se que, havendo a elevação na expectativa de vida dos brasileiros, a demanda por recursos cresce em proporção inversa a disponibilidade de receitas a serem distribuídas no país, uma vez que essa faixa etária normalmente reduz sua contribuição fiscal nessa etapa da vida.

A distribuição normal da receita total per capita dos municípios baianos, que expressa uma probabilidade de freqüência conjunta para os pares de valores das variáveis "receita total" e "população" associada a uma distribuição simétrica em torno da média, demonstra que, existem municípios com receitas totais em proporções diferenciadas de suas demandas sociais, acima ou abaixo da média esperada, uns com mais recursos per capita - geralmente os municípios menores que possuem entre 10 e 30 mil habitantes - e outros com menos - os municípios maiores, especialmente a partir de 30 mil habitantes. Dessa forma, a receita total per capita observada no ano de 2004 não acompanha simetricamente a distribuição normal orçada. 
Ressalta-se que as receitas per capita também variam em função das atividades econômicas desenvolvidas em cada município, podendo gerar um incremento de suas receitas totais. Ao contrário do que deveria ocorrer, não se considera a composição das diferentes receitas fiscais recebidas pelos governos locais para se realizar as transferências redistributivas, bem como para atender a demanda por bens e serviços públicos nos municípios baianos. Exemplificam essa distorção, municípios baianos que possuem menor demanda populacional, como Lajedão, ou maior capacidade econômica, como Camaçari. Esses dados ratificam o entendimento de que o FPM apresenta resultados menos efetivos, considerando apenas o fator populacional, incentivando o surgimento de municípios menores e agravando os problemas sociais das médias e grandes cidades.

A pesquisa aplicada permitiu constatar que os municípios baianos apresentam duas situações antagônicas. Por um lado, têm-se aquelas cidades que possuem IDS menores do que a média estadual, enquanto na outra esfera se encontram os municípios que conseguem IDS acima ou muito acima da média e que, muitas vezes, dispõem de menos receitas públicas a sua disposição. Outra questão que merece destaque na avaliação do IDS desses municípios é que a melhora ou piora nesse indicador não representa uma variação proporcional em todos os índices que o compõem (INS, INE, ISB, IRMCH). Por exemplo, um município pode ter tido o melhor índice de saúde do Estado, por ter aplicado os recursos de forma eficiente, e possuir o pior IDS dentre os municípios baianos. Portanto, os municípios baianos ainda dispõem da contribuição do governo estadual e federal na prestação de serviços sociais, cujos recursos não estão contabilizados no montante a ser distribuído, ao menos nesse estudo, uma vez que não se identificou base de dados detalhada contendo a referida informação.

As análises de correlação e regressão permitiram comprovar, numericamente, se existe relação entre as receitas totais per capita reais e os IDS dos municípios do Estado da Bahia, bem como o cálculo do percentual da variação, explicada pelo modelo exposto a seguir, e a variação total:

a) Variável dependente explicada (y) = IDS; e Variável independente explicativa $(\mathrm{x})=$ receita per capita real;

b) Valores médios do IDS e da receita per capita real, respectivamente: 5003 e R\$634;

c) Coeficiente de correlação linear de Pearson (r): 0,216 e Coeficiente de determinação $\left(r^{2}\right)$ : 0,046;

d) Reta de regressão $=$ modelo que descreve a relação entre as duas variáveis $(x)$ e $(y)$, expressa da seguinte forma: $y=a+b . x$; onde $a=$ intercepto da reta no eixo y (valor constante do IDS) e $b=$ coeficiente angular ou inclinação da reta (coeficiente de variação da receita per capita real);

e) Valores dos coeficientes: $a=4.973$ e $b=0,051$;

f) Substituindo os valores, tem-se a seguinte reta de regressão: $y=4973+$ 0,051.x, onde para cada valor da receita per capita, um valor diferente para o IDS.

Assim sendo, constatou-se que existe uma dispersão nos valores obtidos com o cruzamento das informações, ao qual se permite concluir que não existe relação numérica linear entre as receitas per capita reais e os IDS nos municípios baianos. Ademais, o coeficiente de determinação $\left(r^{2}\right)$ indica que apenas $4 \%$ da variação total do IDS é explicada pela receita per capita real, o que representa que o ajuste linear não apresenta uma boa qualidade. 
Na presente investigação, verificou-se que alguns dos municípios baianos possuem IDS mais elevados do que outros que estão localizados em diferentes faixas de receitas per capita, comprovando que existe grande variação na efetividade da aplicação dos recursos públicos por variados motivos. Portanto, a qualidade do gasto público, avaliada através da aplicação da receita total no atendimento das necessidades sociais, não é uniforme em todos os municípios do Estado da Bahia, conforme se pode comprovar, também, com o ranking dessas cidades quanto à disposição do IDS e da receita per capita, utilizando como base o ano de 2004:



Portanto, confirma-se que vários municípios que dispõem de recursos suficientes para atender às demandas sociais e demonstrar efetividade na utilização do gasto público, não apresentam melhoria proporcional em seus indicadores de desenvolvimento social, tais como, as cidades de São Francisco do Conde, Madre de Deus e Pojuca. Enquanto existem outros municípios, como Alagoinhas e Teixeira de Freitas, que se destacam por estarem entre os quinze que possuem os melhores IDS, ao tempo em que estão abaixo dos duzentos maiores recebedores de recursos públicos no Estado da Bahia.

\section{Comelrusões}

Cabe ressaltar que a efetiva distribuição de receita entre os diversos municípios do Estado da Bahia apresenta elevadíssima disparidade, em função da variação de seu componente mais significativo, as transferências federais e estaduais, que representam em média em torno de $80 \%$ das receitas totais. Configura-se, portanto, um quadro muito distante de uma condição de equidade, proporcionando a algumas comunidades municipais o acesso a elevados montantes de receita, enquanto a outras é destinado um volume até 20 vezes menor, considerada a proporcionalidade com o seu número de habitantes. Confirmam-se, portanto, os argumentos de Morais (2001), Resende (2006), Lucas (2010) e Resende (2012), que reconhecem as elevadas assimetrias vigentes e apontam para a necessidade de uma urgente reforma do sistema federativo pátrio.

Não obstante ao fato das transferências representarem a maior parcela da receita pública dos municípios do Estado da Bahia, a exemplo do que ocorre no restante do país, a dependência das receitas próprias (derivadas do esforço fiscal) para o financiamento dos seus gastos, se eleva na mesma proporção que o tamanho de suas populações. Isto ocorre por que a maior parcela dos fundos de participação se destina ao financiamento dos gastos de municípios menores, que chegam a possuir o dobro de recursos públicos em comparação com as suas necessidades sociais, avaliadas pelo fator populacional. 
Vale destacar que as diferentes formas de se repartir a receita pública (devolução tributária, transferências compensatórias, fundos setoriais, e fundos redistributivos) entre os níveis de governo e a existência de diferentes capacidades econômicas e fiscais locais, desestimulam a cooperação entre os municípios do Estado da Bahia, que preferem buscar soluções mais próximas às suas especificidades e possibilidades financeiras. No tocante às transferências voluntárias, que não possuem obrigatoriedade legal, repassadas pela União e Estado para os municípios baianos, nota-se um incremento durante o período estudado. Entretanto, percebe-se um desequilíbrio nos repasses de receitas públicas para esses municípios, apontando para uma condição de dependência política.

Neste contexto, a qualidade do gasto público nos municípios baianos não se mostra satisfatória, o que é evidenciado pela baixa correlação constatada entre a disponibilidade de receita per capita e os seus correspondentes indicadores de desenvolvimento social. Desta forma, a incapacidade de gestão administrativa associada à insuficiência de recursos per capita tem propiciado a existência de municípios com receita bem superior às suas necessidades sociais, que, no entanto não dispõem de um IDS aceitável, ao tempo em que outros, mesmo com uma menor disponibilidade de receita, conseguem ultrapassar os níveis de desenvolvimento social dos primeiros.

Tais constatações, no entanto, podem comportar alguma distorção em razão desta pesquisa não alcançar os gastos diretos realizados pelos governos federal e estadual em cada município. Esta é certamente uma limitação que precisará ser ultrapassada em uma pesquisa subsequente.

Cabe destacar ainda que, embora a descentralização fiscal possa favorecer a prestação eficaz de serviços públicos, alinhada às preferências e custos locais em uma sociedade, é elevado o risco de que tais benefícios sejam anulados pela insuficiência de capacidade administrativa nas administrações municipais e pelas assimetrias nos mecanismos de distribuição de receita entre estas.

Por último, registra-se como maior implicação dos resultados aqui obtidos, a constatação da imperativa necessidade de revisão dos normativos constitucionais e infraconstitucionais que conformam a distribuição de receita entre os diversos municípios do Estado e, certamente também do país, de modo a ensejar um maior equilíbrio e justiça social na efetiva prestação dos serviços públicos. Esta redefinição necessita levar em consideração as receitas disponíveis e a capacidade total de gastos de cada município, formulando metodologias de cálculo que considerem todas as fontes de recursos, os custos e preferências locais, e as capacidades arrecadatórias de cada ente federado, inclusive visando identificar e compatibilizar atribuições e encargos colidentes.

\section{Referêrincials}

ABRUCIO, Fernando Luiz. A coordenação federativa no Brasil: a experiência do período FHC e os desafios do governo Lula. Revista de Sociologia e Política, Curitiba, n. 24, jun. 2005. Disponível em: <http://www.scielo.br/scielo.

php?script $=$ sci_arttext\&pid $=$ S0104-44782005000100005\&lng $=$ en\&nrm $=$ iso $>$. Acesso em: 16 ago. 2013.

AFONSO, J. R. R. Las relaciones intergubernamentales dentro de Brasil. Revista de La Cepal, Santiago, p. 135-157, dez. 2004.

AFONSO, J. R. R. Memória da Assembléia Constituinte de 1987/88: as finanças públicas. Revista do BNDES. n. 11, jun. 1999. Disponível em: <http://www.bndes. gov.br/SiteBNDES/export/sites/default/bndes_pt/Galerias/Arquivos/conhecimento/ revista/rev1102.pdf>. Acesso em: 16 ago. 2013.

BIRD, R. Relações fiscais intergovernamentais: princípios universais, aplicações locais. [S.I.: s.n.], [2000]. 1 CD-ROM. 
BRASIL. Constituição (1988). Constituição da República Federativa do Brasil. Brasília, DF: Senado, 1988.

BRASIL. Ministério da Fazenda, Secretaria do Tesouro Nacional, Coordenação-Geral de Contabilidade. Receitas Públicas: manual de procedimentos aplicados à União, Estados, Distrito Federal e Municípios. Brasília, 2005, 177 p.

LIMA, E. C. P. Transferências orçamentárias da União para estados e municípios: determinantes e beneficiários. In: REZENDE, F.; OLIVERA, F. A. (Org.). Descentralização e federalismo fiscal no Brasil: desafios da reforma tributária. Rio de Janeiro: Konrad Adenauer Stiftung, 2003. 336 p.

LUCAS, V. Algumas especificidades da tributação do consumo no Brasil. In: SOUZA, M. C. S.; COELHO, I.; VERSIANI, F. R.; TANNURI PIANTO, M. E. (Org.). Economia Pública Brasileira. Brasília, ESAF, 2010. 619 p.

BRASIL. Ministério da Fazenda. Tesouro Nacional. Perfil e evolução das finanças municipais 1998-2005. Versão preliminar não submetida à discussão prévia. Brasília, 2006, 86 p. Disponível em: <http://www.tesouro.fazenda.gov.br>. Acesso em: 15 set. 2007.

MORAES, M. R. As relações intergovernamentais na República Federal da Alemanha: uma análise econômico-institucional. São Paulo: Fundação Konrad Adenauer, 2001. 384 p.

MUSGRAVE, R.A. Teoria das finanças públicas. Tradução Auriphebo Berrance Simões. São Paulo: Atlas, 1974. 383 p.

OATES, W. Federalismo fiscal. Tradução Pablo Perez Jimenez. Madrid: Instituto de estudios de administracion local, 1977. 323 p. (Coleccion Nuevo Urbanismo).

OLIVEIRA, F.A. Transferências orçamentárias da União para estados e municípios: determinantes e beneficiários. In: REZENDE, F.; OLIVERA, F.A (Org.). Descentralização e federalismo fiscal no Brasil: desafios da reforma tributária. Rio de Janeiro: Konrad Adenauer Stiftung, 2003. 336 p.

PRADO, S. et al. Partilha de recursos na Federação Brasileira. São Paulo: FUNDAP/ FAPESP/IPEA, 2003. (Coleção Federalismo no Brasil)

PRADO, S. Aspectos da Guerra Fiscal no Brasil. São Paulo: Edição FUNDAP/IPEA, 2000. Distribuição intergovernamental de recursos na federação brasileira. In: $\overline{R E Z E N D E}$, F.; OLIVERA, F. A. (Org.). Descentralização e federalismo fiscal no Brasil: desafios da reforma tributária. Rio de Janeiro: Konrad Adenauer Stiftung, 2003. $336 \mathrm{p}$.

. Financiamento do gasto social em federações: vinculação e programas nacionais. In: FÓRUM Fiscal dos Estados Brasileiros. Transferências intergovernamentais na federação brasileira: avaliação e alternativas de reforma", São Paulo, Fundação Getúlio Vargas, v. 3, n. 6, p. 38-48, 2006.

. Competição fiscal e desequilíbrios regionais. In: FÓRUM FISCAL DOS ESTADOS BRASILEIROS, 2006. São Paulo: FGV, 2006. 1 CD-ROM.

. Federalismo, encargos e poderes: uma visão geral. In: FÓRUM FISCAL DOS ESTADOS BRASILEIROS, 2006. São Paulo: FGV, 2006. 1 CD-ROM.

Distribuição de recursos fiscais em federações. In: FÓRUM FISCAL DOS ESTADOS BRASILEIROS, 2006. São Paulo: FGV, 2006. 1 CD-ROM.

Competição fiscal: uma visão geral introdutória do contexto internacional. In: FÓRUM FISCAL DOS ESTADOS BRASILEIROS, 2006. São Paulo: FGV, 2006. 1 CD-ROM. Partilha de recursos na Federação Brasileira. In: FÓRUM FISCAL DOS ESTADOS BRASILEIROS, 2006. São Paulo: FGV, 2006. 1 CD-ROM. 
PRINCHAK, R. F. Transferências constitucionais de efeito redistributivo e indicadores sociais dos municípios baianos no período 1998/2000: uma causalidade complexa. 2004. Dissertação (Mestrado em Administração) - Escola de Administração, Universidade Federal da Bahia, Salvador, 2004.

REZENDE, F.; AFONSO, J. R. R. A federação brasileira: desafios e perspectivas.

In: . (Org.). Federalismo e integração econômica regional:

desafios para o Mercosul. Rio de Janeiro: Konrad Adenauer Stiftun, FGV, 2004, p. 301-336.

REZENDE, F.; OLIVEIRA, F. A. (Org.). Descentralização e federalismo fiscal no Brasil: desafios da reforma tributária. Rio de Janeiro: Konrad Adenauer Stiftung, 2003. 333 p.

REZENDE, F. (Org.). Desafios do federalismo fiscal. Rio de Janeiro: Editora FGV, 2006. $116 \mathrm{p}$.

REZENDE, F. Reforma Fiscal e equidade social. Rio de Janeiro: Editora FGV, 2012. $143 \mathrm{p}$.

SILVA, M. S. Teoria do federalismo fiscal: notas sobre as contribuições de Oates, Musgrave, Shah e Ter-Minassian. Nova economia, Belo Horizonte, v. 15, n. 1, p. 117-137, jan.-abr. 2005. Disponível em: <http://www.face.ufmg.br/ novaeconomia/sumarios/v15n1/150105.pdf>. Acesso em: 10 maio 2006.

SOUZA, C. Redemocratização, federalismo e gasto social no Brasil: tendências recentes. In: ENCONTRO ANUAL DA ASSOCIAÇÃO NACIONAL DE PÓS-GRADUAÇÃO EM CIÊNCIAS SOCIAIS - ANPCS. GT03: ESTRUTURA SOCIAL E DESIGUALDADE, 24., 1999, Rio de Janeiro. Anais... Rio de Janeiro, 1999. 1 CD-ROM.

SUPERINTENDÊNCIA DE ESTUDOS ECONÔMICOS E SOCIAIS DA BAHIA - SEI. Perfil financeiro dos municípios baianos 2001-2004. Salvador, v. 5, 2008. Disponível em: $<$ http://www.sei.ba.gov.br/index.php?option=com_content\&view=article\&id =75\&It emid=110>. Acesso em: $01 \mathrm{dez} .2008$.

TER-MINASSIAN, T. Relações fiscais intergovernamentais sob uma perspectiva macroeconômica: uma visão geral. [S.I.: s.n.], [1997]. 24 p. 1 CD-ROM.

\section{Submissão 21/10/2011 \\ Aprovação 03/04/2013}

